\title{
Lionello Sozzi, Rome n'est plus Rome. La polémique anti-italienne et autres essais sur la Renaissance, suivis de La dignité de l'homme
}

\section{Dario Cecchetti}

\section{(2) OpenEdition \\ Journals}

Edizione digitale

URL: https://journals.openedition.org/studifrancesi/37357

DOI: $10.4000 /$ studifrancesi.37357

ISSN: 2421-5856

\section{Editore}

Rosenberg \& Sellier

\section{Edizione cartacea}

Data di pubblicazione: 15 décembre 2004

Paginazione: 587-588

ISSN: 0039-2944

\section{Notizia bibliografica digitale}

Dario Cecchetti, «Lionello Sozzi, Rome n'est plus Rome. La polémique anti-italienne et autres essais sur la Renaissance, suivis de La dignité de l'homme», Studi Francesi [Online], 144 (XLVIII | III) | 2004, online dal 30 novembre 2015, consultato il 08 mai 2021. URL: http://journals.openedition.org/studifrancesi/ 37357 ; DOI: https://doi.org/10.4000/studifrancesi.37357

Questo documento è stato generato automaticamente il 8 mai 2021.

\section{cc) $($ ) $\ominus$}

Studi Francesi è distribuita con Licenza Creative Commons Attribuzione - Non commerciale - Non opere derivate 4.0 Internazionale. 


\title{
Lionello Sozzi, Rome n'est plus Rome. La polémique anti-italienne et autres essais sur la Renaissance, suivis de La dignité de l'homme
}

\author{
Dario Cecchetti
}

\section{NOTIZIA}

LIONELLO SOZZI, Rome n'est plus Rome. La polémique anti-italienne et autres essais sur la Renaissance, suivis de La dignité de l'homme, Paris, Champion («Études et Essais sur la Renaissance», LXI), 2002, pp. 538.

1 Lionello Sozzi raccoglie qui una serie di studi sul Rinascimento francese che coprono una quarantina d'anni di ricerche e seguono tre filoni: 1) la polemica anti-italiana; 2) la novellistica, nelle sue componenti originali e nei rapporti con la tradizione italiana; 3) l'elaborazione del concetto di dignitas hominis. Malgrado l'ampiezza dell'arco temporale in cui questi studi sono stati scritti, si tratta di un corpus profondamente compatto che testimonia coerenza di interessi e organicità di ricerche, intorno al problema dei rapporti fra cultura italiana e francese nel Cinquecento. Le ricerche sull'antiitalianismo (La polémique anti-italienne en France au seizième siècle, pp. 9-84; Éloquence et vérité: un aspect de la polémique anti-italienne, pp. 85-109; La polémique anti-italienne dans l'œuvre narrative d'Henri Estienne, pp. 111-126) sottolineano come alla diffusione straordinaria della cultura italiana oltralpe corrisponda una reazione che concerne soprattutto la vita politica, economica, religiosa e morale, reazione peraltro che «corrisponde alla presa di coscienza di un'originalità e tradisce la volontà di rivendicare l'autonomia culturale della Francia, il prestigio delle sue tradizioni, la sua egemonia sul piano politico» (p. 84). 
2 Strettamente connessi al discorso sull'italianismo sono anche gli studi consacrati alla novella e alla narrazione in prosa in genere (La nouvelle française au quinzième siècle, pp. 127-142; L'influence italienne sur le conte français du seizième siècle, pp. 143-166; Les facéties $d u$ Pogge et leur diffusion en France, pp. 167-180; L'intention du conteur: des textes introductifs aux recueils de nouvelles, pp. 181-197; Tendences politiques et sociales chez les conteurs $d u$ seizième siècle, pp. 199-220; Les sources italiennes du 'Parangon de nouvelles', pp. 221-236; Rabelais, Philelphe et le 'fumet du rôti', pp. 237-250; L'espace intérieur dans l' 'Heptaméron', pp. 251-260; La satire du monde intellectuel dans les contes de Des Périers, pp. 261-283). Autore di una importante monografia su Bonaventure Des Périers che è anche un contributo fondamentale e indispensabile allo studio della novellistica cinquecentesca (pubblicata nel 1965, riproposta da Slatkine nel 1998: cfr. questi «Studi», 134, 2001, pp. 354-357), Sozzi in questi saggi apporta elementi di chiarimento e documentazione sull'influsso dei grandi modelli italiani, da Boccaccio a Bandello, sottolineando anche il ruolo esercitato dagli umanisti neolatini, come Poggio, e dalla tradizione delle facetiae. Inoltre, nel disegnare una poetica del conte ispirata, sì, ai citati modelli ma orientata in autori del peso di Marguerite de Navarre e di Bonaventure Des Périers in direzioni satiriche, religiose e morali nel solco di una cultura tipicamente francese, evidenzia l'originalità profonda della narrativa d'oltralpe. Due saggi concernenti la poesia di Des Périers (Remarques sur la poésie religieuse de Des Périers, pp. 285-307; De l'errance au contentement: nouvelles remarques sur Des Périers poète, pp. 309-317) e un saggio sul dibattito sul «meraviglioso» nell'epica (L'influence en France des épopées italiennes et le débat sur le merveilleux, pp. 319-336) affrontano problemi di influenze e originalità nel campo della poesia.

3 Un'ultima sezione (pp. 339-513) raccoglie gli studi consacrati al tema della dignitas hominis nella cultura francese del Cinquecento. Già pubblicati nel 1997 in un'edizione difficilmente reperibile (Torino, Il Segnalibro Editore), trovano ora, aumentati di un saggio (Présence de l'hermétisme dans le 'Cinquiesme Livre', pp. 479-499), una sede più accessibile. Anche in questo caso l'indagine concerne in gran parte i rapporti con la cultura italiana dell'Umanesimo (Manetti, Pico, Ficino) - allargati alla tradizione classica greco-latina, alla patristica, all'ermetismo, a tutte le manifestazioni della prisca theologia, ai pensatori francesi del XII secolo, a Nicola Cusano - e si giova dell'apporto di studi antropologici che permettono di riconoscere la persistenza di antichi miti (l'uomo pianta celeste, l'uomo microcosmo), di patterns culturali, perseguendo il dipanarsi, sempre mutato e sempre identico, del concetto di dignitas fin nei testi della contemporaneità. Lo studioso, quindi, non può che rallegrarsi di avere a sua disposizione, qui riuniti, strumenti indispensabili per la ricerca del cinquecentista. 